\title{
QUANDO CINDERELA TERÁ SUAS PRÓPRIAS ROUPAS? A NECESSÁRIA RECUSA À TEORIA GERAL DO PROCESSO
}

\author{
Aury Lopes Jr. ${ }^{1}$
}

\begin{abstract}
RESUMO
O Direito Processual Penal possui categorias jurídicas próprias, diferenciadas do Direito Processual Civil, não desvelando, uma teoria geral única, todo o fenômeno do primeiro. Necessidade do processo, liberdade, relação de poder, acusação, conteúdos diferenciados de ação e jurisdição, requisitos das cautelares e das nulidades, são alguns exemplos da necessidade de recusa de uma teoria geral.
\end{abstract}

PALAVRAS-CHAVE: Direito Processual Penal. Teoria Geral Própria. Categorias Jurídicas Específicas.

\section{ABSTRACT}

The Criminal Procedure Law has its own, different legal categories of Civil Procedure, revealing not a single general theory, the whole phenomenon of the first. Need process, freedom, power relationship, prosecution, differentiated contents of action and jurisdiction, and the requirements of the precautionary nonentities, are some examples of the need for refusal of a general theory.

KEYWORDS: Criminal Procedural Law. Own General Theory. Specific Categories Legal.

Era uma vez três irmãs, que tinham em comum, pelo menos, um dos progenitores: chamavam-se a ciência do Direito Penal, a ciência do Processo Penal e a ciência do Processo Civil. E ocorreu que a segunda, em comparação com as demais, que eram belas e prósperas, teve uma infância e uma adolescência desleixada, abandonada. Durante mui-

1 Doutor em Direito Processual Penal pela Universidad Complutense de Madrid. Professor Titular de Direito Processual Penal da PUCRS. Professor Titular no Programa de Pós-Graduação em Ciências Penais, Mestrado e Doutorado da PUCRS. <www.aurylopes.com.br>. 
to tempo, dividiu com a primeira o mesmo quarto. A terceira, bela e sedutora, ganhou o mundo e despertou todas as atenções.

Assim começa Carnelutti, que com sua genialidade escreveu em 1946 um breve, mas brilhante, artigo (infelizmente pouco lido no Brasil), intitulado "Cenerentola"2 (a Cinderela, da conhecida fábula infantil).

O processo penal segue sendo a irmã preterida, que sempre teve de se contentar com as sobras das outras duas. Durante muito tempo, foi visto como um mero apêndice do Direito Penal. Evolui um pouco rumo à autonomia, é verdade, mas continua sendo preterido. Basta ver que não se tem notícia, na história acadêmica, de que o processo penal tivesse sido ministrado ao longo de dois anos, como costumeiramente o é o Direito Penal. Se compararmos com o processo civil então, a distância é ainda maior.

Mas, em relação ao Direito Penal, a autonomia obtida é suficiente, até porque, como define Carnelutti, delito e pena são como cara e coroa da mesma moeda. Como o são Direito Penal e Processual Penal. Mas o problema maior está na relação com o processo civil. O processo penal, como a Cinderela, sempre foi preterido, tendo de se contentar em utilizar as roupas velhas de sua irmã. Mais do que vestimentas usadas, eram vestes produzidas para sua irmã (não para ela). A irmã favorita aqui, corporificada pelo processo civil, tem uma superioridade científica e dogmática inegável.

Tinha razão Bettiol, como reconhece Carnelutti, ${ }^{3}$ de que assistimos inertes a um pancivilismo. E isso nasce na academia, com as famigeradas disciplinas de "Teoria Geral do Processo", tradicionalmente ministradas por processualistas civis que pouco sabem e pouco falam do processo penal e, quando o fazem, é com um olhar e discurso completamente viciado.

Nessa linha, no Brasil, entre os pioneiros críticos está Tucci, que principia o desvelamento do fracasso da Teoria Geral do Processo a partir da desconstrução do conceito de lide (e sua consequente irrelevância) para o processo penal, passando pela demonstração da necessidade de se conceber o conceito de jurisdição penal (para além das categorias de jurisdição voluntária e litigiosa) e o próprio repensar a ação (ação judiciária e ação da parte).

Aponta o autor, ainda criticando a Teoria Geral do Processo, que "esse, aliás, foi um dos (poucos, raros) aspectos negativos da grandiosa obra de José Frederico Marques, ao transplantar (sem, ou, às vezes, com modestos, avaros, retoques) institutos de processo

2 Originariamente publicado na Rivista di Diritto Processuale, v. 1, parte 1, p. 7378. Em espanhol, foi publicado com o título "La Cenicienta", na obra Cuestiones sobre el Proceso Penal, p. 1521.

3 Carnelutti teve uma produção científica bastante ampla, prolixa até, escrevendo do Direito Comercial ao Direito Penal, passando pelo Processo Civil e pelo Processo Penal. Natural que cometesse, como de fato cometeu, diversos tropeços nessa longuíssima caminhada dogmática. Também caiu diversas vezes em contradição. Em casos assim, é preciso conhecer também o autor das obras, para não fazer equivocados juízos a priori. Fazemos essa advertência porque, em que pese no final da vida ter feito verdadeiras declarações de amor ao Direito Penal e ao Processo Penal, lutando por sua evolução e valorização, também foi ele um defensor da equivocada Teoria Unitária (Teoria Geral do Processo), pensando ser o conceito de lide algo unificador. Logo, la cenicienta deve ser compreendida nesse contexto (e nesses conflitos científicos que ele mesmo vivia). 
civil para o processo penal, numa nítida adaptação dos Elementos de direito processual penal às Instituições de direito processual civil [...] incorporando-se numa prolixa e confusa concepção, que poderia ser denominada teoria civil do processo penal [...]".4

Como adverte Coutinho, ${ }^{5}$ outro antigo crítico da Teoria Unitária, "teoria geral do processo é engodo; teoria geral é a do processo civil e, a partir dela, as demais". Ou seja, pensam tudo desde o lugar do processo civil, com um olhar viciado, que conduz a um engessamento do processo penal nas estruturas do processo civil.

Todo um erro de pensar, que podem ser transmitidas e aplicadas no processo penal as categorias do processo civil, como se fossem as roupas da irmã mais velha, cujas mangas se dobram, para caber na irmã preterida. É a velha falta de respeito, a que se referia Goldschmidt, às categorias jurídicas próprias do processo penal.

Contudo, há chegado o momento (e se vão mais de 60 anos do trabalho de Carnelutti) de desvelar a diversidade fenomenológica (e metodológica) das duas irmãs processuais $^{6}$ e compreender que o processo penal possui suas categorias jurídicas próprias, sua diversidade inerente, e que não mais se contenta em usar as vestes da irmã.

Como explica Carnelutti, o processo civil é, nove de cada dez vezes, um processo de sujeitos que "têm", e, quando um dos dois não tem, aspira muito "ter". É o processo do "meu" e do "teu", o que está em jogo é a propriedade, é uma relação coisificada, diria Simmel $^{7}$ (muito antes e muito além dos juristas).

O processo civil é o cenário da riqueza (de quem possui), ao passo que no processo penal, cada vez mais, é o processo de quem não tem, do excluído. Isso contribui para o estigma da gata borralheira, mas não justifica.

No processo penal, em (radical) câmbio, do que estamos tratando? Não é do ter, mas sim da liberdade. No lugar da coisa, pensase na liberdade, de quem, tendo, está na iminência de perder, ou que já não tendo pode recuperá-la ou perdê-la ainda mais. Trata-se de voltar para casa ou ser encarcerado. Como adverte Carnelutti, é com a liberdade o que verdadeiramente se joga no processo penal. "Al juez penal se le pide, como al juez civil, algo que nos falta y de lo cual no podemos prescindir; $y$ es mucho más grave el defecto de libertad que el defecto de propiedad."

Significa dizer que ao juiz penal não se pede, como ao juiz civil, algo que nos falta, o tal "bem da vida" como se referem os civilistas. É a própria vida que está em jogo. Para

\footnotetext{
4 TUCCI, Rogério Lauria. Teoria do direito processual penal, p. 54.

5 COUTINHO, Jacinto Nelson de Miranda. A lide e o conteúdo do processo penal, p. 119.

6 No mesmo sentido, Andres De La Oliva Santos, na obra coletiva Derecho Procesal Penal, p. 51.

7 Aqui estamos fazendo alusão ao complexo pensamento de Simmel, quando, já em 1896, escreveu sobre O dinheiro na cultura moderna, demonstrando o processo de coisificação da humanidade. Importante, ainda, a leitura de Ruth Gauer ( $O$ reino da estupidez e o reino da razão, p. 146 e ss.), quando, abordando Simmel, explica que a "morte do homem" foi diagnosticada quando o autor analisou o papel do dinheiro na sociedade e a separação entre as culturas subjetiva e objetiva. Essa coisificação do ser humano levou ao domínio da coisa sobre o homem. Como explica Gauer, o dinheiro é o Deus moderno, onipotente e onipresente, uma unidade e referência, que une a todos. "Sua busca é a sua falta, produz o ritmo nervoso e o estresse da vida moderna. Que novo tipo de vida o dinheiro constitui?”
} 
o autor, tanto ao juiz penal como ao juiz civil, compete dar a cada um o seu. A (imensa) diferença está em que no penal é dispor do próprio "ser", ao passo que no civil é o "ter".

Não se pode esquecer, ainda, como adverte certeiramente Cirino dos Santos, ${ }^{8}$ que

“[...] o processo penal não se constitui processo de partes livres e iguais - como o processo civil, por exemplo, dominado pela liberdade de partes, em situação de igualdade processual -, mas uma relação de poder instituída pelo Estado com a finalidade de descobrir a verdade de fatos criminosos e punir os autores considerados culpados".

São a ausência de liberdade e a relação de poder instituída (em contraste com a liberdade e a igualdade) os elementos fundantes de uma diferença insuperável entre o processo civil e o penal.

Em relação ao Direito Penal, a autonomia obtida é suficiente, até porque, como define Carnelutti, delito e pena são como cara e coroa da mesma moeda. Como o são Direito Penal e Processual Penal, unidos pelo "princípio da necessidade" iudicio - tão bem definido por Gomez Orbaneja. O Direito Civil se realiza todo dia sem Processo Civil (negócios jurídicos etc.), pois é autoexecutável, tem realidade concreta. O Direito Civil só chama o Processo Civil quando houver uma lide, carnelutianamente pensada como um conflito de interesses qualificado por uma pretensão resistida. Já no campo penal tudo é diferente. O Direito Penal não é autoexecutável e não tem realidade concreta fora do processo. É castrado. Se alguém for vítima de um crime, a pena não cai direta e imediatamente na cabeça do agressor. O Direito Penal não tem eficácia imediata e precisa, necessariamente, do Processo Penal para se efetivar, pois o processo é um caminho necessário e inafastável para chegar na pena.

E não se invoquem as causas de exclusão da ilicitude ou culpabilidade para dizer que são manifestações da autoexecutividade do direito penal porque é uma premissa equivocada. As causas de 'exclusão', como o próprio nome diz, afastam um elemento fundante da própria existência do 'crime', portanto, são elementos negativos. Não é a realização do direito penal, mas obstáculos à existência do crime. E, mesmo elas, somente terão sua plena existência quando reconhecidas no processo.

Por isso, o princípio da necessidade demarca uma diferença insuperável entre penal e civil. Vejamos alguns rápidos exemplos (existe muito mais...) da (dis)torção conceitual e absurdos processuais realizados em nome da Teoria Geral do Processo:

a) No Processo Penal, forma é garantia e limite de poder, pois aqui se exerce o poder de punir em detrimento da liberdade. É um poder limitado e condicionado, que precisa se legitimar pelo respeito às regras do jogo. Logo, não se deve

\footnotetext{
CIRINO DOS SANTOS, Juarez. Direito penal - Parte geral. Rio de Janeiro: Lumen Juris, 2006, p. 655.

9 Sobre o tema e demais fundamentos do processo penal, consultar nossa obra Direito processual penal. 11. ed. São Paulo: Saraiva, 2014.
} 
importar a tal 'instrumentalidade das formas' e 'informalismo processual', pois aqui o fenômeno é completamente diferente.

b) Precisamos abandonar as teorias da ação, pois tudo o que se escreveu desde a polêmica Windscheid-Muther, passando pelas teorias da ação como direito abstrato (Plosz), como direito concreto (Wach) ou direito potestativo (Chiovenda) não pode ser aplicado ao processo penal sem muito ajuste, muita costura, quase uma roupa nova. Como afirmar que ação é um direito público, abstrato e autônomo? Se for assim, alguém pode processar alguém diretamente, sem nada de provas, de forma totalmente autônoma e abstrata? No processo civil, sim. No processo penal, nem pensar, pois é preciso desde logo demonstrar um mínimo de concretude, de indícios razoáveis de autoria e materialidade. E o juízo de mérito, ainda que superficialmente, é feito desde logo. Portanto, os conceitos de autonomia e abstração têm que ser repensados, senão completamente redesenhados. Mais do que isso, penso que precisamos elaborar uma 'teoria da acusação', adequada à realidade do processo penal.

c) Dizer que as condições da ação no Processo Penal são interesse e possibilidade jurídica do pedido é um erro, repetido sem maior reflexão por grande parte da doutrina. Como falar em 'interesse' se aqui a regra é a necessidade? Discutir 'interesse de agir' e outros civilismos é desconhecer o que é processo penal. Pior é tentar salvar o 'interesse' através do entulhamento conceitual, atribuindo um conteúdo a essa categoria que ela não comporta. Esse é o erro mais comum: para tentar salvar uma inadequada categoria do Processo Civil, vão metendo definições que extrapolam os limites semânticos e de sentidos possíveis. Para salvar uma categoria inadequada não fazem outra coisa que matá-la, mas mantendo o mesmo 'nome', para fazer jus a 'teoria geral'. E a tal "possibilidade jurídica do pedido"? O que é isso? Outra categoria inadequada, até porque, no processo penal, o pedido é sempre o mesmo... Mas e o que fazer para salvar um conceito erroneamente transplantado? Entupo-o de coisas que não lhe pertencem. Falam em suporte probatório mínimo, em indícios razoáveis de autoria e materialidade etc., ou seja, de outras coisas, que nada têm a ver com possibilidade jurídica do pedido. Enfim, temos que levar as condições da ação a sério, para evitar essa enxurrada de acusações infundadas que presenciamos, servindo apenas para estigmatizar e punir ilegitimamente. Juízes que operam na lógica civilista não fazem a imprescindível 'filtragem' para evitar acusações infundadas. A TGP estimula o acusar infundado (afinal, é direito 'autônomo e abstrato') e o recebimento burocrático, deixando a análise do 'mérito' para o final, quando, no processo penal, ab initio precisamos demonstrar of fumus commissi delicti (abstrato, mas conexo instrumentalmente ao caso penal, diria Jacinto Coutinho). 
d) Lide penal? Outro conceito imprestável e que não faz qualquer sentido aqui. Inclusive, é um erro falar em 'pretensão punitiva', na medida em que o Ministério Público não atua no processo penal como 'credor' (cível) que pede a adjudicação de um direito próprio. Ao MP não compete o poder de punir, mas de promover a punição. Por isso, no processo penal não existe lide, até porque não existe 'exigência punitiva' que possa ser satisfeita fora do processo (de novo o princ. da necessidade). O MP exerce uma 'pretensão acusatória' e, o juiz, o pode condicionado de punir. Sobre o objeto do processo, trataremos adiante.

e) E o conceito de jurisdição? Tem outra dimensão no processo penal, para além do poder-dever, é uma garantia fundamental, é limite de poder, é fator de legitimação, sendo que o papel do juiz no Processo Penal é distinto daquele exercido no processo civil. Por isso, a garantia do juiz natural é mais sensível aqui, até porque, o juiz é o guardião da eficácia do sistema de garantias da constituição e que lá está para limitar poder e garantir o débil submetido ao processo. Dessarte, grave problema existe na matriz da TGP e suas noções de competência relativa e absoluta, desconsiderando que no processo penal não há espaço para a (in)competência relativa. É por isso que estão manipulando a competência no Processo Penal, esquecendo que o direito de ser julgado pelo 'meu juiz', competente em razão de matéria, pessoa e (principalmente) lugar, é fundamental. A dimensão do julgamento penal é completamente diferente do julgamento civil, pois não podemos esquecer que o 'caso penal' é uma lesão a um bem jurídico tutelado em um determinado lugar. Ou alguém vai dizer que o fato de um júri ser na cidade "A" ou na cidade "B" é irrelevante? Óbvio que não. Mas o que sabe a TGP de crime e júri?

f) Juiz natural e imparcial. A estrutura acusatória ou inquisitória do processo penal (como veremos adiante) é um dos temas mais relevantes e diretamente ligado ao princípio supremo do processo: a imparcialidade do julgador. A posição do juiz é fundante no Processo Penal, desde sua perspectiva sistêmica (e, como tal, complexa) para garantia da imparcialidade. Como ensinam os mais de 30 anos de jurisprudência do Tribunal Europeu de Direitos Humanos, juiz que vai atrás da prova está contaminado e não pode julgar. Trata-se de uma preocupação específica do processo penal e desconhecida pela processo civil e a TGP.

g) Juiz natural e imparcial II. A prova da alegação incumbe a quem alega? Claro que não! No Processo Penal não existe 'distribuição de carga probatória', senão 'atribuição' integral ao acusador, pois operamos desde algo que os civilistas não conhecem e tampouco compreendem: presunção de inocência.

h) Juiz natural e imparcial III: Julgar em dúvida razoável é um dilema, especialmente quando os adeptos da TGP resolvem 'distribuir' cargas probatórias e, em dúvida, resolvem 'ir atrás da prova'. Pronto, está criado o problema. 
O ativismo judicial mata o Processo Penal. Juiz ator, que vai atrás da prova, desequilibra a balança, mata o contraditório e fulmina a imparcialidade. Sim, aqui a situação é bem complexa...Então o que fazer? Compreender que no processo penal muita gente queimou na fogueira (a TGP não conhece Eymerich e o Directorum Inquisitorum) para chegarmos no in dubio pro reo. Sem compreender esse complexo 'caldo cultural' e os valores em jogo, especialmente o in dubio pro reo, como regra de julgamento, e a presunção de inocência, como regra de tratamento, é impossível analisar a questão.

i) "Fumus boni iuris" e "periculum in mora"? É impactante ver um juiz (de)formado pela TGP decretar uma prisão preventiva porque presentes o fumus boni iuris e o periculum in mora. Ora, quando alguém é cautelarmente ${ }^{10}$ preso é porque praticou um fato aparentemente criminoso. Desde quando isso é 'fumaça de bom direito'? Crime é bom direito? Reparem no absurdo da transmissão de categorias! E qual é o fundamento da prisão? Perigo da demora? O réu vai 'perecer'? Claro que não... Mas não faltará alguém para - incorrendo em grave reducionismo - dizer que é apenas 'palavra'. Mais um erro. Para nós, no Direito Penal e Processual Penal, palavra é limite, palavra é legalidade, as palavras 'dizem coisas' e nós trabalhamos de lupa em cima do que diz a palavra e do que o intérprete diz que a palavra diz. Logo, nunca se diga que é 'apenas' palavra, pois a palavra é tudo.

j) Poder geral de cautela? De vez em quando algum juiz 'cria' medidas restritivas de direitos fundamentais invocando o CPC (!) e o 'poder geral de cautela' (ilustre desconhecido para o CPP). Mais um absurdo de quem desconhece que o sistema penal se funda no Princípio da Legalidade, na reserva de lei certa, taxativa e estrita. Não se admite criar 'punição' por analogia! Sim, mas é isso que fazem os que operam na lógica da TGP.

k) Vou decretar a revelia do réu! Não raras vezes ouvimos isso em uma audiência. Gostariamos de perguntar: vai inverter a carga da prova também, Excelência? Elementar que não. A categoria 'revelia' é absolutamente inadequada e inexistente no processo penal, sendo figura típica do processo civil, carregada de sentido negativo, impondo ainda a 'presunção de veracidade' sobre os fatos não contestados e outras consequências inadequadas ao processo penal. A inatividade processual (incluindo a omissão e a ausência) não encontra qualquer tipo de reprovação jurídica. Não conduz a nenhuma presunção, exceto a de inocência, que continua inabalável. O não agir probatório do réu não conduz a nenhum tipo de punição processual ou presunção de culpa. Não existe um dever de agir para o imputado para que se lhe possa punir pela omissão. ${ }^{11}$

10 LOPES JR., Aury. Prisões cautelares. 4. ed. São Paulo: Saraiva, 2014.

11 Sobre essa e as demais questões mencionadas neste tópico, sugerimos a leitura de nossa obra Direito processual penal, publicada pela editora Saraiva, onde esses temas são tratados com mais profundidade. 
1) Esse recurso especial/extraordinário não tem efeito suspensivo! Até recentemente, por culpa da TGP, as pessoas eram 'automaticamente' presas ao ingressar com esses recursos, porque a Lei no 8.038 (civilista...) diz que tais recursos não têm efeito suspensivo. Mas desde quando prender alguém ou deixar em liberdade está situado na dimensão de efeito recursal? Desde nunca! É um absurdo gerado pela cultura da TGP, que desconhece a presunção de inocência!

m) Nulidade relativa. Essa é a fatura mais alta que a TGP cobra do processo penal: acabaram com a teoria das nulidades pela importação do pomposo pas nullité sans grief. Tão pomposo quanto inadequado e danoso. Iniciemos por um princípio básico - desconhecido pela TGP, por elementar: forma é garantia. $\mathrm{O}$ ritual judiciário está constituído, essencialmente, por discursos e, no sistema acusatório, forma é garantia, pois Processo Penal é exercício de poder e todo poder tende a ser autoritário. Violou a forma? Como regra, violou uma garantia do cidadão. E o tal 'prejuízo'? É uma cláusula genérica, de conteúdo vago impreciso e indeterminado, que vai encontrar referencial naquilo que quiser o juiz (autoritarismo-decisionismo-espaços impróprios de discricionariedade, conforme Lenio Streck). Como dito, no processo penal existe exercício condicionado e limitado de poder, sob pena de autoritarismo. E esse limite vem dado pela 'forma'. Portanto, flexibilizar a forma, é abrir a porta para que os agentes estatais exerçam o poder sem limite, em franco detrimento dos espaços de liberdade. É rasgar o Princípio da Legalidade e toda a teoria da tipicidade dos atos processuais. É rasgar a Constituição. Por culpa da TGP, está chancelado o vale-tudo processual. O decisionismo se legitima na TGP. Eu-tribunal anulo o que eu quiser, quando eu quiser. E viva a teoria geral do processo!

Portanto, em rápidas pinceladas está demonstrada (e desenhada) a necessidade de se recusar a Teoria Geral do Processo e assimilar o necessário respeito às categorias jurídicas próprias do processo penal.

Voltando ao início carnelutiano, Cinderela é uma boa irmã e não aspira a uma superioridade em relação às outras, senão, unicamente, a uma afirmação de paridade. $\mathrm{O}$ Processo Civil, ao contrário do que sempre se fez, não serve para compreender o que é o Processo Penal: serve para compreender o que não é. Daí porque, com todo o respeito, basta de Teoria Geral do Processo.

\section{Referências}

CIRINO DOS SANTOS, Juarez. Direito penal: parte geral. Rio de Janeiro: Lumen Juris, 2006.

CARNELUTTI, Francesco. Cuestiones sobre el proceso penal. Buenos Aires: Librería del Foro, 1960. 
COUTINHO, Jacinto Nelson de Miranda. A lide e o conteúdo do processo penal. Curitiba: Juruá, 1998.

GAUER, Ruth. O reino da estupidez e o reino da razão. Rio de Janeiro: Lumen Juris, 2005.

LOPES JR., Aury. Direito processual penal. 11. ed. São Paulo: Saraiva, 2014 a.

. Prisões cautelares. 4. ed. São Paulo: Saraiva, 2014b.

OLIVA SANTOS, Andres de La (Coord.). Derecho procesal penal. Madri: CEURA, 1997.

SIMMEL, Georg. O dinheiro na cultura moderna. In: SOUZA, Jessé; ÖELZE, Berthold (Orgs.). Simmel e a modernidade. Brasília: UnB, 2005.

TUCCI, Rogério Lauria. Teoria do direito processual penal: jurisdição, ação e processo penal. São Paulo: Revista dos Tribunais, 2003. p. 256.

Como citar este artigo:

LOPES JR., Aury. Quando Cinderela terá suas próprias roupas? A necessária recusa à teoria geral do processo. Revista Brasileira de Direito Processual Penal, Porto Alegre, vol. 1, n. 1, p. 230-237, 2015. http://dx.doi.org/10.22197/rbdpp.v1i1.13 